\title{
Grynfeltt Hernia with Spiegel Hernia: Report of a Rarely Encountered Case Running Head: Grynfeltt Hernia
}

\author{
Yusuf Sevim, M.D., FTBS; Huseyin Berkem, M.D; Erdinc Cetinkaya, M.D; Siyar Ersoz, M.D; \\ Adnan Yilmaz, M.D; Cem Emir Guldogan, M.D \\ Ankara Numune Training and Research Hospital, Department of General Surgery, Division of Colorectal \\ Surgery, Ankara, Turkey \\ *Corresponding Author: Yusuf Sevim, Ankara Numune Training and Research Hospital, Department of \\ General Surgery, Division of Colorectal Surgery, Ankara, Turkey.E-mail: yusufsevim@gmail.com
}

Received: February 1, 2017

Accepted: February 18, 2017

Published: March 1, 2017

\begin{abstract}
:
Background: Grynfeltt hernia is a rare abdominal wall hernia. We aimed to report a case with Grynfeltt and Spigelian hernia together.

Case Report: We report a 56-year-old female patient with Grynfeltt and Spigelian hernias. The patient admitted with right lumbar and left lower abdominal bulging and identified Grynfeltt and Spigelian hernias by computed tomography. We repaired the hernia with onlay mesh. The patient had no complication on postoperative month 1.

Conclusions: The choice of surgical technique in management of Grynfeltt hernia depends on the size of fascial defect and experience of the surgeon. Rarely Spigelian hernia may accompany to the Grynfelt hernia.
\end{abstract}

\section{INTRODUCTION}

Lumbar hernia accounts less than $2 \%$ of all abdominal hernias (1). Grynfeltt hernia was described as the hernia of superior lumbar triangle. The lumbar region is the area bounded superiorly by the $12^{\text {th }}$ thoracic rib, inferiorly by iliac crest, medially by the erector spinae muscles, and laterally by the external oblique muscles. One of the weak areas of lumbar region is Grynfeltt triangle formed superiorly by the $12^{\text {th }}$ thoracic rib, medially by quadratus lumborum muscle, laterally by the internal oblique muscle. The common symptoms of lumbar hernias are lumbar bulging, and pain. In this report, we aimed to present our case with Grynfeltt hernia accompanying Spigelian hernia and discuss its surgical management.

\section{CASE}

A 56-year-old female patient admitted to our clinic with right lumbar and lower quadrant mass and lumbar pain. The mass was occurred approximately 2 years before the admission. Medical history revealed that she had total abdominal hysterectomy and bilateral salphingo - oophorectomy with pfannenstiel incision for benign disease. There were no additional remarkable features in her history. Total abdominal ultrasonography (US) and abdominal computed tomography (CT) were performed to identify fascial defects and additional pathologies. We detected hepatosteatosis and multiple renal cortical cysts by US, and CT detected fascial defects at the site of Spigelian and Grynfeltt hernia (Figure 1A-B), and also wall thickenings at antrum and duodenal bulbus, so we performed upper gastrointestinal endoscopy and detected enterogastric bile reflux and erosive antral gastritis, and medical treatment was given. Single dose of $1 \mathrm{gr}$ cefazolin IV was used for prophylaxis after induction of anesthesia. The surgical approach was open with a lumbar incision in the left lateral position, and the protruded fat tissue was released from adjacent tissue. The protruded tissue was excised and the defect was identified. The defect was approximately $2 \mathrm{~cm}$ in size (Figure 2). The defect was closured primarily with 0 polydioxanonesutures (Ethicon PDS II ${ }^{\mathrm{TM}}$; Ethicon, Somerville, New Jersey, USA) and we placed prolene mesh onlay. After the position changed to the supine for Spigelian hernia, transvers incision was made and hernia sac was liberated of its adhesions and reduced. The defect was repaired primarily with using prolene mesh onlay, and the hemovac drains were 
placed to the operation sites. There were no complications occurred, the drains were withdrawn and patient was discharged on postoperative day 1 . She had no complaints and recurrence of hernia on postoperative week 1 and month 1.

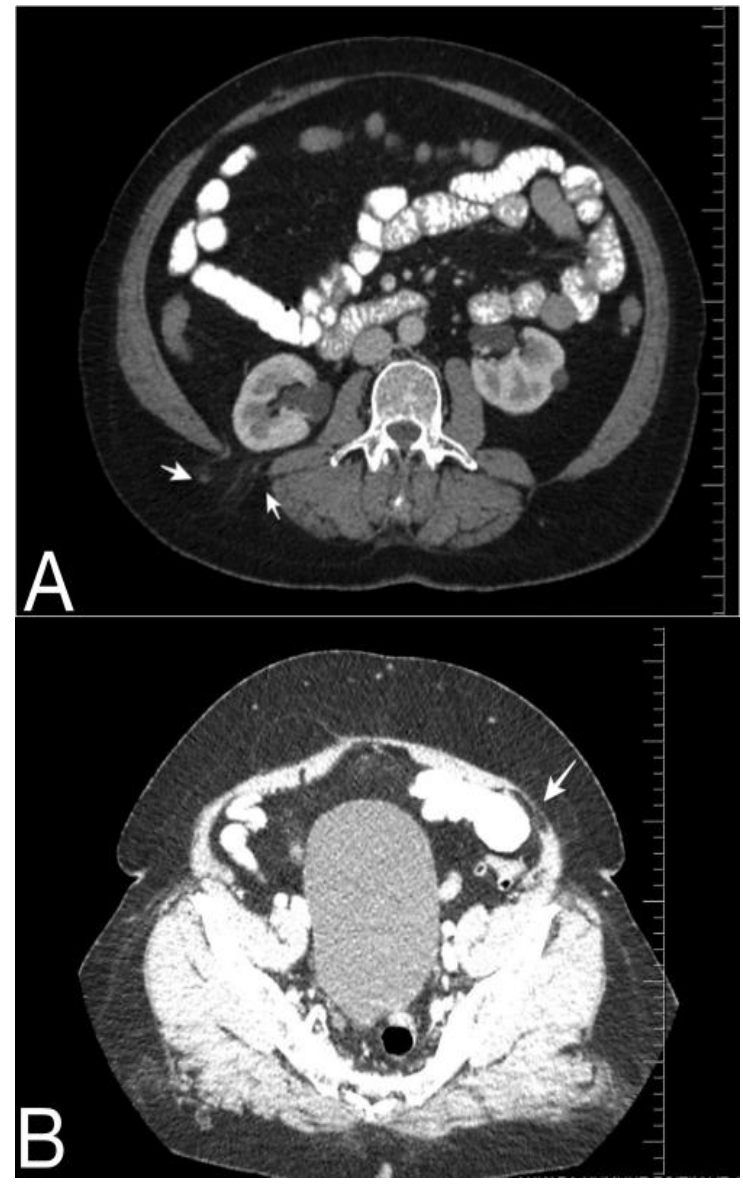

Fig1. The herniation of fat tissues at the sites of Grynfeltt (A), and Spigelian (B) regions detected by using computed tomography.

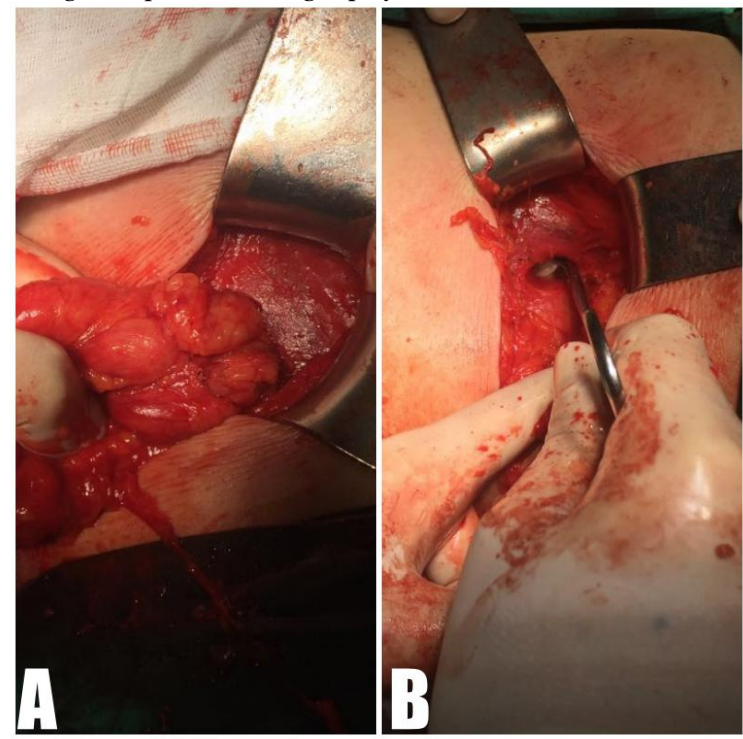

Fig2A/B. Intra-operative views of Grynfeltt hernia. (The left side of the picture is cranial side of the patient.)

\section{DISCUSSION}

Lumbar hernias are typically classified as a type of abdominal wall hernia, but anatomically these hernias are lying outside of the abdominal wall. Lumbar hernia may be congenital or spontaneous, and mostly related to prior surgery especially partial or complete nephrectomy (2). The rare Grynfeltt hernia occurs at superior lumbar triangle. The most common symptom is posterolateral bulging increases in size with strenuous activity, and can present as vague back pain, bowel, or urinary obstruction $(3,4)$. Hernia repairs require the use of mesh.

There are 3 well-described areas of weakness: just below the rib that the fascia transversalis is not covered by external oblique muscle, the area of fascial penetration of $12^{\text {th }}$ dorsal intercostal neurovascular pedicle, and between Henle ligament and the inferior edge of the rib. Protruding of intra-abdominal tissues from these areas form Grynfeltt hernia. Grynfeltt hernia may be congenital or acquired. Most of these hernias are acquired (80\%), and acquired hernias are subdivided into two: spontaneous (primary) and seconder hernias. Advanced age, obesity, extreme thinness, intense slimming, presence of chronic debilitating disease, muscular atrophy, chronic bronchitis, wound infection and postoperative sepsis are the risk factors associated with occurrence of primary hernia (4).Direct contusion, crushing, surgical lesions or infections of pelvic bones and ribs, hepatic abscesses, infected retroperitoneal hematomas, and infectious processes altering the integrity of the lumbosacral fascia are responsible in mechanisms of pathogenesis of secondary acquired hernias $(3,4)$.Preoperative imaging procedures are usually performed to identify the fascial defects, and eliminate the other pathologies. The CT findings are helpful especially in patients with atypical clinics. Because CT indicates the anatomic relations in lumbar region so well, it may be the only imaging procedure necessary to make the diagnosis of a lumbar hernia (5). This procedure can be helpful in the assessment of symptomatic patients with lumbar incision to differentiate postincisional muscular weakness and intercostal neuralgia from lumbar hernia. Extracoelomic locations of intra-abdominal organs are defined well with CT, so obscure hernias can be detected with CT scan. We used CT scan in our case and defined Spigelian hernia addition to lumbar hernia, and alsowall thickenings at antrum and duodenal bulbus. Just 
like in our case, CT can give additional information about intra - abdominal pathologies. Surgical management is the only therapeutic option and avoids the patients from complications of lumbar hernia. Open surgical treatment is usually used, but laparoscopic hernia repairs may be used in treatment of lumbar hernias. Loukas and colleagues classified Grynfeltt's triangle according to its measuresinto 4 groups postmortemly: type 0 when no triangle was formed, type I $<5 \mathrm{~cm}^{2}$, type II $5-15 \mathrm{~cm}^{2}$, and type III $>15 \mathrm{~cm}^{2}(6)$. After that, Moreno-Egea et al. proposed preoperative classification of Grynfeltt hernia with surgical implications, and named the groups from $\mathrm{A}$ to $\mathrm{D}(4)$. They used size, location, contents, etiology, muscular atrophy, and recurrence (Table 1).Group D was used to classify the pseudo-hernias. According to this classification our case was typeA and the surgery may be performed both open or laparoscopically. Lumbar hernia is best approached with the patient in lateral decubitus position, and mesh onlay for large defects are proposed. There is limited data in the literature about using mesh because of limited cases. So, generally surgeons tend to use mesh repair.

Table1. Classification of lumbar hernias (4) and proposal of surgery

\begin{tabular}{|l|l|l|l|l|}
\hline \multicolumn{1}{|c|}{ Characteristic } & \multicolumn{1}{c|}{ A } & \multicolumn{1}{c|}{ B } & \multicolumn{1}{c|}{ D } \\
\hline Size & $<5$ & $5-15$ & $>15$ & \\
\hline Location & Superior & Inferior & Diffuse & \\
\hline Contents & Extraperitoneal fat & Visceral & Visceral & \\
\hline Etiology & Spontaneous & Incisional & Traumatic & Severe \\
\hline Muscular atrophy & No (minor) & Mild & Severe & \\
\hline Recurrence & No & Yes (open) & Yes (laparoscopic) & $\begin{array}{l}\text { Open approach } \\
\text { (double mesh) }\end{array}$ \\
\hline Surgical approach & Open or laparoscopy & $\begin{array}{l}\text { Intraperitoneal } \\
\text { laparoscopy }\end{array}$ & Open & \multicolumn{1}{c|}{ (a) } \\
\hline
\end{tabular}

Laparoscopical treatments of lumbar hernias have some advantages such as less postoperative pain, shorter hospital stay, and good cosmetic and functional results $(1,7)$. On the other hand most of the surgeons are not familiar with laparoscopic view of the lumbar area for this rare hernia, so advanced laparoscopic skill and experiences are required in laparoscopic lumbar hernia repair. Also there are some various surgical techniques for lumbar hernia repair such as primary closure, fascial or gluteal flaps, and the use of mesh either underlay, inlay, or onlay $(8,9)$. In our case that patient had Grynfeltt and Spigelian hernias together, we chose mesh repair onlay although the defect was small in order to avoid from recurrence. Another important technique is the sandwich technique described by Sahoo and colleagues (9). They mentioned that 4 patients treated with this technique without any intraoperative and postoperative complications in a median 6 months follow-up. After that some additional cases reported with sandwich technique (10).

\section{CONCLUSION}

Lumbar hernia is a rarely seen abdominal wall hernia. There are limited data about the treatment and postoperative results. We think that the choice of surgical technique depends on the size of fascial defect and experience of the surgeon. Rarely Spigelian hernia may accompany to the Grynfeltt hernia, so detailed physical examination is required. Accumulating data with case reports and case series is going to increase the information about the management of Grynfeltt hernia.

\section{CONFLICT OF INTEREST}

All authors declare that we have no commercial associations or sources of support that might pose a conflict of interest.

\section{REFERENCES}

[1] Patnaik S, Nayak TN, Patro S. Lumbar Hernia: A Case Report and Review of Literature. Int $\mathbf{J}$ Sci Study. 2015;3(8):188-90.

[2] Walgamage TB, Ramesh BS, Alsawafi Y. Case report and review of lumbar hernia. Int $\mathbf{J}$ Surg Case Rep. 2015;6C:230-2.

[3] Cesar D, Valadao M, Murrahe RJ. Grynfelt hernia: case report and literature review. Hernia. 2012;16(1):107-11.

[4] Moreno-Egea A, Baena EG, Calle MC, Martinez JA, Albasini JL. Controversies in the current management of lumbar hernias. Arch Surg. 2007;142(1):82-8.

[5] Baker ME, Weinerth JL, Andriani RT, Cohan RH, Dunnick NR. Lumbar hernia: diagnosis by CT. AJR Am J Roentgenol. 1987;148(3):565-7. 
[6] Loukas M, El-Zammar D, Shoja MM, Tubbs RS, Zhan L, Protyniak B, et al. The clinical anatomy of the triangle of Grynfeltt. Hernia. 2008;12(3):227-31.

[7] Suarez S, Hernandez JD. Laparoscopic repair of a lumbar hernia: report of a case and extensive review of the literature. Surg Endosc. 2013;27(9):3421-9.

[8] Mismar A, Al-Ardah M, Albsoul N, Younes N. Underlay mesh repair for spontaneous lumbar hernia. Int J Surg Case Rep. 2013;4(6):534-6.
[9] Sahoo MR. Sandwich technique of closure of lumbar hernia: a novel technique. International Journal of Case Reports and Images (IJCRI). 2013;4(5):243-7.

[10] Ploneda-Valencia CF, Cordero-Estrada E, Castaneda-Gonzalez LG, Sainz-Escarrega VH, Varela-Munoz O, De la Cerda-Trujillo LF, et al. Grynfelt-Lesshaft hernia a case report and review of the literature. Ann Med Surg (Lond). 2016;7:104-6.

Citation: Yusuf Sevim, Huseyin Berkem, Erdinc Cetinkaya, Siyar Ersoz, Adnan Yilmaz \& Cem Emir Guldogan. Grynfeltt Hernia with Spiegel Hernia: Report of a Rarely Encountered Case Running Head: Grynfeltt Hernia. ARC Journal of Surgery.2017; 3(1):1-4. doi:dx.doi.org/10.20431/2455-572X.0301001.

Copyright: (c) 2017 Authors. This is an open-access article distributed under the terms of the Creative Commons Attribution License, which permits unrestricted use, distribution, and reproduction in any medium, provided the original author and source are credited. 